\title{
A mean stress model of fatigue life of metal materials under multiaxial loading
}

\begin{abstract}
Due to the complexity of multiaxial fatigue damage of metal materials, up to date, it is still a challenging task to establish a multiaxial fatigue model with influence of different mean stress. In this paper, a linear mean stress model is presented on basis of the multiaxial model of fatigue life of metal materials by Liu and Yan. By using the experimental data of fatigue life of metal materials reported in the literature, the model is systematically validated.
\end{abstract}

Keywords: multiaxial fatigue, mean stress, metallic materials
Volume 5 Issue 2 - 202I

\author{
Xiangqiao Yan \\ Center for composite materials and structure, Harbin institute \\ of technology, China
}

\begin{abstract}
Correspondence: Xiangqiao Yan, Center for composite materials and structure, Harbin institute of technology, I50080, China, Tel 086-|37048029|5, Fax 86-45|-864|4|45,
\end{abstract} Email yanxiangqiao406@।63.com

Received: July 15, 2020 | Published: April 26, 2021

\section{Introduction}

Many critical mechanical components experience multiaxial cyclic loading during their service life, such as railroad wheels, crankshafts, axles, and turbine blades, etc. Different from the uniaxial fatigue problem, the multiaxial fatigue problem is more complex due to the complex stress states. In recent decades, a significant amount of research has been devoted to acquire a better understanding of the failure mechanisms under multiaxial loading, including theoretical model study (e.g., a stress invariant method, ${ }^{1,5-10}$ and a critical plane method, ${ }^{11-13}$ fatigue tests of metallic materials under multiaxial loading (e.g., fatigue test for engineering steels by $\mathrm{Gough}^{3}$ and fatigue of wrought high-tensile alloy steel by Frith. ${ }^{4}$ Due to the complexity of multiaxial fatigue damage of metal materials, up to date, it is still a challenging task to establish a multiaxial fatigue model with influence of different mean stress. In this paper, a linear mean stress model is presented on basis of the multiaxial model of fatigue life of metal materials by Liu \& Yan ${ }^{1,2}$ By using the experimental data of fatigue life of metal materials reported in the literature, the model is systematically validated.

\section{A multiaxial mean stress model}

In this section, the Marin's mean stress model proposed by Liu and Yan ${ }^{1}$ is first described briefly. Then a linear mean stress model is given. After the reader reads this paper, the reason that the linear mean stress model is presented by the author is naturally understood.

\section{A Marin's mean stress model}

A model for fatigue life prediction under multiaxial stress states can be expressed mathematically as follows:

$$
F\left(\sigma_{e a}, \sigma_{e m}, \rho, N, c_{1}, c_{2}, \ldots\right)=0
$$

where $\sigma_{e}$ is a mechanical parameter which is a measure of stress states in multiaxial loading, and here, the von Mises equivalent stress is adopted; $\sigma_{e a}$ and $\sigma_{e m}$ are the amplitude and the mean value of the equivalent stress, respectively. Multiaxial parameter $\rho$ is defined as follows:

$$
\rho=\frac{\sigma_{11, a}}{\sigma_{e, a}}
$$

where $\sigma_{11, a}$ is the amplitude of the first invariant of stress tensor. It is evident that, for the axial and shear fatigue loading, the value of the multiaxial parameter $\rho$ is equal to 1 and 0 , respectively. $c_{1}, c_{2}, \ldots$ in the Eq. (1) are material coefficients, which are varied with the multiaxial parameter $\rho$. Based on the previous wide investigations (e.g., Tao and $\mathrm{Xia}^{14}$ and Marin's general equation ${ }^{15}$ ) of engineering rules suitable for predicting the mean stress effect under the bending loading, it is assumed here that the model of multiaxial fatigue life has the following form:

$$
\log \sigma_{e a}\left(1-\alpha_{\rho} \frac{\sigma_{e m}}{\sigma_{e a}}\right)^{n_{\rho}}=A_{\rho} \log N+C_{\rho}
$$

where $A_{\rho}, C_{\rho}, \alpha_{\rho}, n_{\rho}$ are material parameters dependent on the multiaxial parameter $\rho$. For the axial and shear fatigue loading, Eq. (3) can be simplified as, respectively:

$$
\log \sigma_{a}\left(1-\alpha_{1} \frac{\sigma_{m}}{\sigma_{a}}\right)^{n_{1}}=A_{1} \log N+C_{1}
$$

And

$$
\log \sqrt{3} \tau_{a}\left(1-\alpha_{0} \frac{\tau_{m}}{\tau_{a}}\right)^{n_{0}}=A_{0} \log N+C_{0}
$$

In the absence of mean stress, the Eq. (3) is simplified as:

$$
\log \sigma_{e a}=A_{\rho} \log N+C_{\rho}
$$

Thus under the axial and shear fatigue loading, the Eqs (4) and (5) can be written as respectively:

$$
\log \sigma_{a}=A_{1} \log N+C_{1}
$$

And

$$
\log \sqrt{3} \tau_{a}=A_{0} \log N+C_{0}
$$

Eq. (7) is the well known $S-N$ curve equation. Eq. (8) is the variant form of the $S$ - $N$ curve equation under the shear fatigue condition, which can be written as: 


$$
\log \tau_{a}=A_{0}^{\prime} \log N+C_{0}^{\prime}
$$

in which $A_{0}^{\prime}$ and $A_{0}$ are related with $A_{0}$ and $C_{0}$ through the following relationships:

$$
A_{0}^{\prime}=A_{0}, C_{0}=C_{0}-\sqrt{3}
$$

In view of the complexity of fatigue life analysis in the multiaxial stress states, and also taking into account that the existing literature has accumulated a large number of fatigue experimental data under the axial and shear loading, from the point of application, it is assumed that the material parameters in Eq. (3) can be obtained by interpolating the material parameters in Eqs (4) and (5), i.e.:

$$
\begin{aligned}
& A_{\rho}=A_{1} \cdot \rho+A_{0} \cdot(1-\rho) \\
& C_{\rho}=C_{1} \cdot \rho+C_{0} \cdot(1-\rho) \\
& \alpha_{\rho}=\alpha_{1} \cdot \rho+\alpha_{0} \cdot(1-\rho) \\
& n_{\rho}=n_{1} \cdot \rho+n_{0} \cdot(1-\rho)
\end{aligned}
$$

In this way, multiaxial fatigue life can be directly estimated from the stress invariant parameter and the multiaxial S-N curve with the attention on mean stress effect.

\section{A linear mean stress model}

According to the Marin's mean stress model of multiaxial loading, i.e., Eq.(3), a linear mean stress model presented in this paper is as follows:

$$
\log \sigma_{e a}\left(\beta_{\rho}-\gamma_{\rho} \frac{\sigma_{e m}}{\sigma_{e 0}}\right)=A_{\rho} \log N+C_{\rho}
$$

where

$$
\sigma_{e o}=\sigma_{o}^{\rho}\left(\sqrt{3} \tau_{o}\right)^{(1-\rho)}
$$

in which $\sigma$ and $\tau$ are, respectively, a tensile fatigue limit and a shear fatigue limit. Under the axial and shear fatigue loading, Eq (15) can be written as

$$
\log \sigma_{a}\left(\beta_{1}-\gamma_{1} \frac{\sigma_{m}}{\sigma_{0}}\right)=A_{1} \log N+C_{1}
$$

and

Table I Material constants and R-square of fitted S-N equation under the axial fatigue loading

\begin{tabular}{lccccccc} 
Materials & $A_{1}$ & $C_{1}$ & R-square & $\alpha_{1}$ & $n_{1}$ & $\beta_{1}$ & $\gamma_{1}$ \\
\hline Cast iron & -0.140 & 2.858 & 0.840 & -0.499 & 1.210 & 1.663 & -0.039 \\
I8G2A steel & -0.131 & 3.286 & 0.932 & -12.13 & 0.139 & 1.161 & -0.279 \\
S355J0 alloy steel & -0.177 & 3.535 & 0.893 & -4.316 & 0.215 & 1.059 & -0.343 \\
\hline
\end{tabular}
proposed by Liu \& Yan $^{2}$

$$
\log \sqrt{3} \tau_{a}\left(\beta_{0}-\gamma_{0} \frac{\tau_{m}}{\tau_{0}}\right)=A_{0} \log N+C_{0}
$$

in which $\beta_{1}, \gamma_{1}, \beta_{0}$ and $\gamma_{0}$ are material constants determined by fitting experimental data of fatigue life.

By the way, material parameters and in Eq (15) can be determined by using the interpolation formulas similar to formulas (13) to (14). Eq (16) is a multiaxial fatigue limit prediction equation recently

\section{Experimental verifications and discussions}

Based on the experimental data of fatigue life of metallic materials from literature, in this section, fatigue life analysis will be carried out by using fatigue life prediction equations with the linear mean stress effect and the Marin's mean stress effect. The comparison of two results will be given. In order to quantitatively evaluate the accuracy of the fatigue life prediction, the following error indexes are defined:

$$
\begin{gathered}
E R 1=\frac{\left(N_{c a l}-N_{\exp }\right) \times 100}{N_{\exp }} \\
E R 2=\frac{\left(N_{c a l}^{\prime}-N_{\exp }\right) \times 100}{N_{\exp }} \\
M E R 1=\frac{1}{n} \sum_{i=1}^{n}(E R 1)_{i} \\
M E R 2=\frac{1}{n} \sum_{i=1}^{n}(E R 2)_{i}
\end{gathered}
$$

where $\mathrm{n}$ is the number of experimental cases, $N_{\exp }$ is experimental fatigue life; $N_{c a l}$ and $N_{c a l}$ are computed fatigue lives by the Marin's mean stress model and the linear mean stress model, respectively. In this section, the fatigue life prediction of three metallic materials, Cast iron, 18G2A steel, and S355J0 alloy steel under uniaxial and multiaxial loading are carried out. For the sake of clear discussions, they are described in the forms of examples, respectively. The material constants determined by using the experimental data of fatigue life of these materials are listed in Table $1 \&$ Table 2. Note here material constants, $\sigma_{0}$ and $\tau_{0}$, can be evaluated respectively by means of Eqs (7) and (8). For example, for 18G2A steel, let $N_{f}=2000000$ (cycles), the following two values can be obtained.

$$
\sigma_{0}=286(\mathrm{MPa}), \tau_{0}=188(\mathrm{MPa})
$$


Table 2 Material constants and R-square of fitted S-N equation under the shear fatigue loading

\begin{tabular}{llllllll}
\hline Materials & $C_{0}$ & $C_{0}$ & R-square & $\alpha_{0}$ & $\beta_{0}$ & $\beta_{0}$ & $\gamma_{0}$ \\
\hline Cast iron & -0.074 & 2.887 & 0.965 & -0.604 & 0.700 & 1.357 & -0.044 \\
I8G2A steel & -0.074 & 2.984 & 0.884 & -27.233 & 0.133 & 1.223 & -0.379 \\
S355J0 alloy steel & -0.076 & 2.994 & 0.670 & -138.02 & 0.079 & 1.290 & -0.251 \\
\hline
\end{tabular}

\section{Example I: Cast iron}

For cast iron reported by Berto, Lazzarin \& Tovo ${ }^{16}$ under zero mean stress, predicted results of fatigue life are given in Table 3 . Error ranges of fatigue life are, respectively, $[-47,80](\%),[-41,66](\%)$ and $[-43,28](\%)$, for the axial, shear and multiaxial fatigue loading, which shows that the fatigue lives predicted by means of Eqs (6), (7) and (8) are very satisfactory. Note here that there is an early failure case with a relative error $746 \%$, see Table 3, which should be deleted. Under the axial fatigue loading with mean stress , the error ranges of fatigue life, $E R 1$ and $E R 2$, are, respectively, $[-28,44](\%)$ and [-29,45] (\%), see Table 4, which illustrates that fatigue lives predicted by means of the linear mean stress model, i.e., Eq (17), almost are same as those by means of the Marin's mean stress model, i.e., Eq (4). Under the shear fatigue loading with mean stress, the error ranges of fatigue life, $E R 1$ and $E R 2$, are, respectively, [-34,30] (\%) and [-34,23] (\%), see Table 4, from which it can be seen that accuracy of fatigue lives predicted by using the two mean stress models is very high, and that the fatigue lives predicted by the linear mean stress model, i.e., Eq. (18), are a little better than those by the Marin's mean stress model, i.e., Eq. (5). Under the multiaxial fatigue loading with mean stress, the error ranges of fatigue life, $E R 1$ and $E R 2$, are, respectively, [-72, 30] $(\%)$ and $[-62,-16](\%)$, see Table 4 , which shows that that accuracy of fatigue lives predicted by using the two mean stress models is satisfactory (Table 3).

\section{Example 2: I8G2A steel}

For $18 \mathrm{G} 2 \mathrm{~A}$ steel reported by Gasiak \& Pawliczek ${ }^{17}$, under zero mean stress, predicted results of fatigue life are given in Table 5. Error ranges of fatigue life are, respectively, $[-28,105](\%),[-34,81](\%)$ and $[-54,-13](\%)$, for the axial, shear and multiaxial fatigue loading, which shows that the fatigue lives predicted by means of Eqs (6), (7) and (8) are very satisfactory. Under the axial fatigue loading with mean stress, the error ranges of fatigue life, ER1 and $E R 1$, are, respectively, $[-45,92](\%)$ and $[-40,92](\%)$, see Table 6 , which illustrates that fatigue lives predicted by the linear mean stress model, i.e., Eq (17) almost are same as those by means of the Marin's mean stress model, i.e., Eq (4). Under the shear fatigue loading with mean stress, the error ranges of fatigue life, $E R 1$ and $E R 1$, are, respectively, $[-46,53](\%)$ and $[-54,46](\%)$, see Table 6 , from which it can be seen that accuracy of fatigue lives predicted by using the Marin's mean stress model, i.e., Eq (5) almost is same as that by means of the linear mean stress model, i.e., Eq (18). Under the multiaxial fatigue loading with mean stress, the error ranges of fatigue life, ER1 and $E R 2$, are, respectively, $[-49,172](\%)$ and $[-42,170](\%)$, see Table 7 , which shows that the fatigue lives predicted by using the linear mean stress model, i.e., Eq (15), are a little better than those by the Marin's mean stress model, i.e., Eq (3) (Table 4 -Table 7).

\section{Example 3: S355J0 alloy steel}

For S355J0 alloy steel reported by Gasiak \& Pawliczek ${ }^{18}$ under zero mean stress, predicted results of fatigue life are given in Table 8 . Error ranges of fatigue life are, respectively, $[-25,17](\%)$ and $[-33,81]$ (\%), for the axial and shear fatigue loading, which shows that the fatigue lives predicted by means of Eqs (7) and (8) are very accurate. Under multiaxial fatigue loading, error range of fatigue life, $[-68,-13]$ $(\%)$, is satisfactory. Under the axial fatigue loading with mean stress, the error ranges of fatigue life, $E R 1$ and $E R 2$, are, respectively, [-57, 45] (\%) and [-51,39] (\%), see Table 9, which illustrates that accuracy of fatigue lives predicted by using the two mean stress models is very high, and that the fatigue lives predicted by the linear mean stress model, i.e., Eq (17), are a little better than those by the Marin's mean stress model, i.e., Eq (4). Under the shear fatigue loading with mean stress, the error ranges of fatigue life, $E R 1$ and $E R 2$, are, respectively, $[-42,79](\%)$ and $[-48,86](\%)$, see Table 9 , from which it can be seen that accuracy of fatigue life predicted by using the two mean stress models is very high, and that the fatigue lives predicted by the Marin's mean stress model, i.e., Eq (5), are a little better than those by the linear mean stress model, i.e., Eq (18). Under the multiaxial fatigue loading with mean stress, the error range and the mean error of fatigue lives predicted by using the linear mean stress model, i.e., Eq (15), are, respectively, $[-38,99](\%)$ and $8 \%$, see Table 9, which shows that that accuracy of fatigue lives predicted by using the linear mean stress model is very high. However, the error range and the mean error of fatigue lives predicted by means of the Marin's mean stress model, i.e., Eq (3), are, respectively, [-89,-68] (\%) and -84\%, see Table 9, which shows that the predicted by the Marin's mean stress model is very poor. The comparison of the two results is shown In Figure 1. What is the reason that, under the multiaxial fatigue loading with mean stress, the accuracy of fatigue lives of S355J0 alloy steel predicted by the Marin's mean stress model is very poor? For this, the author observes the material constants listed in Table $1 \&$ Table 2 and finds that, for S355J0 alloy steel, $\alpha_{0}$ is much less than $\alpha_{0},($ $\alpha_{1} / \alpha_{0}=0.03127$, see Table 10), which is the reason that the accuracy of fatigue lives predicted by using the Marin's mean stress model, i.e., Eq. (3), is very poor. In order to further illustrate it, in the following form of Marin's mean stress model:

$$
\log \sigma_{e a}\left(1-\alpha \frac{\sigma_{e m}}{\sigma_{e a}}\right)^{n}=A_{\rho} \log N+C_{\rho}
$$

by letting $\alpha=\alpha_{1}, \alpha=\alpha_{0}$ and $\alpha=\alpha_{0}, n=n_{0} \quad$, fatigue lives predicted are listed in 11 , in which the error ranges are, respectively, $[-60,16](\%)$ and $[-37,188](\%)$, and the mean errors are, respectively, $-21(\%)$ and $38(\%)$ (Table 12). Comparison of detail errors are given in Table 12, from which it can be seen that the accuracy of fatigue lives predicted by using the linear mean stress model, i.e., Eq (15), is much better than that by using the Marin's mean stress model, Eq (3). 
Table 3 Comparison of experimental data and predicted results of fatigue life of Cast iron with zero mean stress

\begin{tabular}{|c|c|c|c|c|c|}
\hline$\sigma_{a}(\mathbf{M P a})$ & $\sigma_{m}(\mathrm{MPa})$ & $\tau_{a}(\mathbf{M P a})$ & $\tau_{m}(\mathbf{M P a})$ & $N_{\exp }$ (Cycles) & $E R(\%)$ \\
\hline 160 & 0 & 0 & 0 & 40,194 & 15 \\
\hline 160 & 0 & 0 & 0 & 86,632 & -47 \\
\hline 130 & 0 & 0 & 0 & 159,000 & 28 \\
\hline 130 & 0 & 0 & 0 & 193,903 & 5 \\
\hline 108.5 & 0 & 0 & 0 & 408,667 & 80 \\
\hline 108.5 & 0 & 0 & 0 & $1,091,520$ & -32 \\
\hline 0 & 0 & 220 & 0 & 10,000 & 36 \\
\hline 0 & 0 & 200 & 0 & 38,500 & 28 \\
\hline 0 & 0 & 200 & 0 & 45,750 & 8 \\
\hline 0 & 0 & 180 & 0 & 338,500 & -39 \\
\hline 0 & 0 & 180 & 0 & 350,000 & -41 \\
\hline 0 & 0 & 180 & 0 & 285,000 & -28 \\
\hline 0 & 0 & 160 & 0 & 980,000 & 3 \\
\hline 0 & 0 & 140 & 0 & $3,698,000$ & 66 \\
\hline 0 & 0 & 140 & 0 & $5,055,500$ & 21 \\
\hline 140 & 0 & 140 & 0 & 16,400 & -43 \\
\hline 130 & 0 & 130 & 0 & 28,500 & -34 \\
\hline 120 & 0 & 120 & 0 & 46,800 & -16 \\
\hline 110 & 0 & 110 & 0 & 103,000 & -14 \\
\hline 100 & 0 & 100 & 0 & 229,000 & -5 \\
\hline 100 & 0 & 100 & 0 & 297,500 & -27 \\
\hline 90 & 0 & 90 & 0 & 68,500 & 746 \\
\hline 90 & 0 & 90 & 0 & 520,000 & 12 \\
\hline 90 & 0 & 90 & 0 & 602,000 & -4 \\
\hline 80 & 0 & 80 & 0 & $\mathrm{I}, 36 \mathrm{I}, 500$ & 28 \\
\hline 80 & 0 & 80 & 0 & $1,998,000$ & -13 \\
\hline
\end{tabular}


Table 4 Comparison of experimental data and predicted results of fatigue life of Cast iron with non-zero mean stress

$\sigma_{a}(\mathrm{MPa}) \quad \sigma_{m}(\mathrm{MPa}) \quad \tau_{a}(\mathrm{MPa}) \quad \tau_{m}(\mathrm{MPa}) \quad N_{\exp }(\mathrm{Cycles}) \quad E R 1(\%) \quad E R 2(\%)$

\begin{tabular}{|c|c|c|c|c|c|c|}
\hline 100 & 100 & 0 & 0 & 46,121 & -13 & -10 \\
\hline 80 & 80 & 0 & 0 & $|36,08|$ & 44 & 45 \\
\hline 70 & 70 & 0 & 0 & 709,456 & -28 & -29 \\
\hline 60 & 60 & 0 & 0 & I,389,28 & 10 & 7 \\
\hline 0 & 0 & 150 & 150 & 21,000 & 30 & 23 \\
\hline 0 & 0 & 140 & 140 & 61,890 & 12 & 9 \\
\hline 0 & 0 & 140 & 140 & 73,000 & -5 & -7 \\
\hline 0 & 0 & 130 & 130 & 286,830 & -34 & -34 \\
\hline 0 & 0 & 120 & 120 & 597,350 & -6 & -4 \\
\hline 0 & 0 & 110 & 110 & $\mathrm{I}, 663,00$ & 9 & 15 \\
\hline 0 & 0 & 110 & 110 & $\mathrm{I}, 720,00$ & 5 & 11 \\
\hline 80 & 80 & 80 & 80 & 43,525 & -5 & -16 \\
\hline 90 & 90 & 90 & 90 & 20,535 & -54 & -41 \\
\hline 60 & 60 & 60 & 60 & $\mathrm{I}, 410,00$ & -4 & -62 \\
\hline 70 & 70 & 70 & 70 & 180,000 & 18 & -29 \\
\hline 70 & 70 & 70 & 70 & 173,000 & 23 & -26 \\
\hline 100 & 100 & 100 & 100 & 9000 & -72 & -49 \\
\hline 60 & 60 & 60 & 60 & $\mathrm{I}, 040,00$ & 30 & -48 \\
\hline
\end{tabular}

Table 5 Comparison of experimental data and predicted results of fatigue life of I8G2A steel with zero mean stress

\begin{tabular}{|c|c|c|c|c|c|}
\hline $\begin{array}{l}\sigma_{a} \\
(\mathbf{M P a})\end{array}$ & $\begin{array}{l}\sigma_{m} \\
(\mathbf{M P a})\end{array}$ & $\begin{array}{l}\tau_{a} \\
(\mathbf{M P a})\end{array}$ & $\begin{array}{l}\tau_{m} \\
(\mathbf{M P a})\end{array}$ & $N_{\text {exp }}$ & $\begin{array}{l}E R \\
\text { (\%) }\end{array}$ \\
\hline 399.6 & 0 & 0 & 0 & 128630 & 22 \\
\hline 399.8 & 0 & 0 & 0 & |5388| & 2 \\
\hline 399.8 & 0 & 0 & 0 & 168309 & -7 \\
\hline 364.1 & 0 & 0 & 0 & 327016 & -3 \\
\hline 365.3 & 0 & 0 & 0 & 375852 & -17 \\
\hline 367 & 0 & 0 & 0 & 415067 & -28 \\
\hline 275 & 0 & 0 & 0 & 1306495 & 105 \\
\hline 275.4 & 0 & 0 & 0 & $2869 \mid 40$ & -8 \\
\hline 275.5 & 0 & 0 & 0 & 3364694 & -21 \\
\hline 0 & 0 & 223 & 0 & 224794 & -10 \\
\hline
\end{tabular}

Citation: Yan X.A mean stress model of fatigue life of metal materials under multiaxial loading. Material Sci \& Eng. 2021;5(2):60-69. DOI: 10.15406/mseij.2021.05.00157 


\begin{tabular}{|c|c|c|c|c|c|}
\hline $\begin{array}{l}\sigma_{a} \\
(\mathbf{M P a})\end{array}$ & $\begin{array}{l}\sigma_{m} \\
(\mathbf{M P a})\end{array}$ & $\begin{array}{l}\tau_{a} \\
\mathbf{( M P a})\end{array}$ & $\begin{array}{l}\tau_{m} \\
(\mathbf{M P a})\end{array}$ & $N_{\exp }$ & $\begin{array}{l}E R \\
\text { (\%) }\end{array}$ \\
\hline 0 & 0 & 222.6 & 0 & 278939 & -26 \\
\hline 0 & 0 & 222.7 & 0 & 310708 & -34 \\
\hline 0 & 0 & 195.7 & 0 & 637980 & 81 \\
\hline 0 & 0 & 195.4 & 0 & 785106 & 50 \\
\hline 0 & 0 & 196.2 & 0 & 874370 & 27 \\
\hline 0 & 0 & 183.9 & 0 & 2296066 & 15 \\
\hline 0 & 0 & 184 & 0 & 3095310 & -15 \\
\hline 0 & 0 & 183 & 0 & 4173870 & -32 \\
\hline 199.7 & 0 & 199.7 & 0 & 168497 & -13 \\
\hline 199.7 & 0 & 199.7 & 0 & 192588 & -24 \\
\hline 199.5 & 0 & 199.5 & 0 & 226543 & -35 \\
\hline 180.2 & 0 & 180.2 & 0 & 609639 & -35 \\
\hline 180.2 & 0 & 180.2 & 0 & 615487 & -36 \\
\hline 180 & 0 & 180 & 0 & 737954 & -46 \\
\hline 164.5 & 0 & 164.5 & 0 & |30374| & -27 \\
\hline 164.6 & 0 & 164.6 & 0 & $|40720|$ & -32 \\
\hline 164.4 & 0 & 164.4 & 0 & 2101434 & -54 \\
\hline
\end{tabular}

Table 6 Comparison of experimental data and predicted results of fatigue life of I8G2A steel with non-zero mean stress (under uniaxial fatigue loading)

\begin{tabular}{|c|c|c|c|c|c|c|}
\hline $\begin{array}{l}\sigma_{a} \\
(\mathbf{M P a})\end{array}$ & $\begin{array}{l}\sigma_{m} \\
(\mathbf{M P a})\end{array}$ & $\begin{array}{l}\tau_{a} \\
(\mathbf{M P a})\end{array}$ & $\begin{array}{l}\tau_{m} \\
\mathbf{( M P a )}\end{array}$ & $N_{\text {exp }}$ & $\underset{(\%)}{E R 1}$ & $\underset{(\%)}{E R 2}$ \\
\hline 369.5 & 123.2 & 0 & 0 & 57172 & -13 & -24 \\
\hline 369.6 & 123.2 & 0 & 0 & 65725 & -24 & -34 \\
\hline 369.1 & 123 & 0 & 0 & 72614 & -31 & -40 \\
\hline 298.3 & 99.4 & 0 & 0 & $|3| 43 \mid$ & 92 & 92 \\
\hline 298.5 & 99.5 & 0 & 0 & 168583 & 49 & 49 \\
\hline 298.5 & 99.5 & 0 & 0 & 178962 & 40 & 41 \\
\hline 268.8 & 89.6 & 0 & 0 & 578316 & -4 & 2 \\
\hline 268.9 & 89.6 & 0 & 0 & $67|48|$ & -17 & -12 \\
\hline 268.9 & 89.6 & 0 & 0 & 712823 & -22 & -17 \\
\hline 247.3 & 82.4 & 0 & 0 & 976665 & 7 & 19 \\
\hline 247.1 & 82.4 & 0 & 0 & 1356769 & -22 & -14 \\
\hline 290.2 & 290.2 & 0 & 0 & 95759 & 31 & 14 \\
\hline 288.6 & 288.6 & 0 & 0 & |3307| & -2 & -14 \\
\hline 265.7 & 265.7 & 0 & 0 & $|570| \mid$ & 56 & 54 \\
\hline 274.3 & 274.3 & 0 & 0 & I 73047 & II & 5 \\
\hline 255 & 255 & 0 & 0 & 241679 & 39 & 45 \\
\hline 254.5 & 254.5 & 0 & 0 & 422196 & -20 & -16 \\
\hline 235.3 & 235.3 & 0 & 0 & 887342 & -31 & -20 \\
\hline 235.4 & 235.4 & 0 & 0 & I I 26890 & -45 & -37 \\
\hline 0 & 0 & 175 & 58.3 & I 57758 & -25 & -35 \\
\hline
\end{tabular}

Citation: Yan X.A mean stress model of fatigue life of metal materials under multiaxial loading. Material Sci \& Eng. 2021;5(2):60-69. DOI: I0.I5406/mseij.202I.05.00I57 


\begin{tabular}{|c|c|c|c|c|c|c|}
\hline $\begin{array}{l}\sigma_{a} \\
(\mathbf{M P a})\end{array}$ & $\begin{array}{l}\sigma_{m} \\
(\mathbf{M P a})\end{array}$ & $\begin{array}{l}\tau_{a} \\
\mathbf{( M P a )}\end{array}$ & $\begin{array}{l}\tau_{m} \\
\mathbf{( M P a )}\end{array}$ & $N_{\exp }$ & $\begin{array}{l}E R 1 \\
\text { (\%) }\end{array}$ & $\begin{array}{l}\text { ER2 } \\
\text { (\%) }\end{array}$ \\
\hline 0 & 0 & 174.5 & 58.2 & 229202 & -46 & -54 \\
\hline 0 & 0 & 151.6 & 50.5 & $55|27|$ & 46 & 47 \\
\hline 0 & 0 & 151.3 & 50.4 & 640123 & 29 & 30 \\
\hline 0 & 0 & 151.3 & 50.4 & 689753 & 20 & 21 \\
\hline 0 & 0 & 138.4 & 46.1 & 2176479 & 25 & 37 \\
\hline 0 & 0 & I38.4 & 46.1 & $3|8792|$ & -15 & -6 \\
\hline 0 & 0 & 138.2 & 138.2 & 356608 & 53 & 46 \\
\hline 0 & 0 & 137.8 & 137.8 & 526773 & 8 & 4 \\
\hline 0 & 0 & 135.4 & 135.4 & 710704 & I & 2 \\
\hline 0 & 0 & 135.2 & 135.2 & 860208 & -15 & -14 \\
\hline 0 & 0 & 131.4 & $13 \mid .4$ & II 23272 & -5 & 3 \\
\hline 0 & 0 & 131.2 & $13 \mid .2$ & 1501895 & -27 & -21 \\
\hline
\end{tabular}

Table 7 Comparison of experimental data and predicted results of fatigue life of I8G2A steel with non-zero mean stress (under multiaxial fatigue loading)

\begin{tabular}{|c|c|c|c|c|c|c|}
\hline$\sigma_{a}(\mathbf{M P a})$ & $\sigma_{m}(\mathrm{MPa})$ & $\tau_{a}(\mathrm{MPa})$ & $\tau_{m}(\mathrm{MPa})$ & $N_{\text {exp }}$ & $E R 1$ (\%) & $E R 2$ (\%) \\
\hline 146.5 & 48.8 & 146.5 & 48.8 & 87304 & 172 & 170 \\
\hline 146.7 & 48.9 & 146.7 & 48.9 & 93327 & $15 \mid$ & 149 \\
\hline 146.5 & 48.8 & 146.5 & 48.8 & 121935 & 95 & 94 \\
\hline 129.8 & 43.3 & 129.8 & 43.3 & 382788 & 100 & 117 \\
\hline 129.8 & 43.3 & 129.8 & 43.3 & $417 \mid 27$ & 83 & 100 \\
\hline 121.4 & 40.5 & 121.4 & 40.5 & |40835| & 4 & 18 \\
\hline 121.4 & 40.5 & 121.4 & 40.5 & $|50567|$ & -3 & II \\
\hline 118.5 & 39.5 & 118.5 & 39.5 & 2317350 & -20 & -8 \\
\hline 118.3 & 39.4 & 118.3 & 39.4 & 3056739 & -39 & -29 \\
\hline 139.4 & 139.4 & 139.4 & 139.4 & 115525 & 3 & -15 \\
\hline 139.4 & 139.4 & 139.4 & 139.4 & 138497 & -14 & -29 \\
\hline 129.2 & 129.2 & 129.2 & 129.2 & 211846 & 17 & 11 \\
\hline 129.5 & 129.5 & 129.5 & 129.5 & 233041 & 4 & -1 \\
\hline 123.2 & 123.2 & 123.2 & 123.2 & 257221 & 53 & 58 \\
\hline 123.2 & 123.2 & 123.2 & 123.2 & 366179 & 7 & 11 \\
\hline 120.9 & 120.9 & 120.9 & 120.9 & 681921 & -31 & -26 \\
\hline 120.9 & 120.9 & 120.9 & 120.9 & 794444 & $-4 \mid$ & -36 \\
\hline 118 & 118 & 118 & 118 & 1165727 & -49 & -43 \\
\hline
\end{tabular}


Table 8 Comparison of experimental data and predicted results of fatigue life of S355J0 alloy steel with zero mean stress

\begin{tabular}{|c|c|c|c|c|c|}
\hline$\sigma_{a}(\mathbf{M P a})$ & $\sigma_{m}(\mathbf{M P a})$ & $\tau_{a}(\mathbf{M P a})$ & $\tau_{m}(\mathbf{M P a})$ & $N_{\text {exp }}$ (Cycles) & $E R(\%)$ \\
\hline 400 & 0 & 0 & 0 & 153000 & 17 \\
\hline 365 & 0 & 0 & 0 & 403000 & -25 \\
\hline 275 & 0 & 0 & 0 & 1295000 & 14 \\
\hline 0 & 0 & 224 & 0 & 300000 & -33 \\
\hline 0 & 0 & 196 & 0 & 632000 & 81 \\
\hline 0 & 0 & 184 & 0 & 3150000 & -17 \\
\hline 200 & 0 & 200 & 0 & 190000 & -13 \\
\hline 183 & 0 & 183 & 0 & 739000 & -55 \\
\hline 167 & 0 & 167 & 0 & 2117000 & -68 \\
\hline
\end{tabular}

Table 9 Comparison of experimental data and predicted results of fatigue life of S355J0 alloy steel with non-zero mean stress

\begin{tabular}{|c|c|c|c|c|c|c|}
\hline $\begin{array}{l}\sigma_{a} \\
(\mathbf{M P a})\end{array}$ & $\begin{array}{l}\sigma_{m} \\
(\mathbf{M P a})\end{array}$ & $\begin{array}{l}\tau_{a} \\
(\mathbf{M P a})\end{array}$ & $\begin{array}{l}\tau_{m} \\
(\mathbf{M P a})\end{array}$ & $\begin{array}{l}N_{\text {exp }} \\
\text { (Cycles) }\end{array}$ & $\begin{array}{l}E R 1 \\
(\%)\end{array}$ & $\begin{array}{l}\text { ER2 } \\
\text { (\%) }\end{array}$ \\
\hline 247 & 82 & 0 & 0 & 1011000 & -9 & 7 \\
\hline 269 & 90 & 0 & 0 & 713000 & -20 & -11 \\
\hline 368 & 123 & 0 & 0 & 72000 & 35 & 21 \\
\hline 236 & 236 & 0 & 0 & 1083000 & -57 & -51 \\
\hline 257 & 257 & 0 & 0 & 246000 & 17 & 19 \\
\hline 269 & 269 & 0 & 0 & 153000 & 45 & 39 \\
\hline 275 & 275 & 0 & 0 & 171000 & 15 & 6 \\
\hline 290 & 290 & 0 & 0 & 131000 & II & -6 \\
\hline 0 & 0 & 139 & 46 & 1043000 & 79 & 86 \\
\hline 0 & 0 & $15 \mid$ & 50 & 670000 & -6 & -7 \\
\hline 0 & 0 & 175 & 58 & 158000 & -42 & -48 \\
\hline 0 & 0 & 133 & 133 & II30000 & -6 & 0 \\
\hline 0 & 0 & 136 & 136 & 850000 & -6 & -4 \\
\hline 0 & 0 & 139 & 139 & 525000 & 14 & 13 \\
\hline 118 & 39 & 118 & 39 & 2356000 & -89 & -28 \\
\hline$|2|$ & 40 & 121 & 40 & 1516000 & -86 & -9 \\
\hline 130 & 43 & 130 & 43 & 378000 & -68 & 99 \\
\hline 121 & $|2|$ & $12 \mid$ & $|2|$ & 803000 & -92 & -38 \\
\hline 124 & 124 & 124 & 124 & 366000 & -86 & 8 \\
\hline 130 & 130 & 130 & 130 & 210000 & -84 & 21 \\
\hline 140 & 140 & 140 & 140 & 117000 & -84 & 8 \\
\hline
\end{tabular}

Citation: Yan X.A mean stress model of fatigue life of metal materials under multiaxial loading. Material Sci \& Eng. 2021;5(2):60-69. 
Table 10 Comparison of material constants used to describe the effect of mean stress on fatigue life

\begin{tabular}{lcccc}
\hline & Marin's mean stress model & \multicolumn{2}{c}{ Linear mean stress model } \\
\hline Materials & $\alpha_{1} / \alpha_{0}$ & $n_{1} / n_{0}$ & $\beta_{1} / \beta_{0}$ & $\gamma_{1} / \gamma_{0}$ \\
Cast iron & 0.826159 & 1.726845 & 1.225497 & 0.88636 \\
I8G2A steel & 0.445415 & 1.045113 & 0.949305 & $0.736 / 48$ \\
S355J0 alloy steel & 0.031271 & 2.697616 & 0.820739 & 1.366534 \\
\hline
\end{tabular}

Table I I Comparison of experimental data and predicted results of fatigue life of S355J0 alloy steel under multiaxial fatigue loading with non-zero mean stress

\begin{tabular}{|c|c|c|c|c|c|c|}
\hline$\sigma_{a}(\mathbf{M P a})$ & $\sigma_{m}(\mathrm{MPa})$ & $\tau_{a}(\mathrm{MPa})$ & $\tau_{m}(\mathbf{M P a})$ & $N_{\text {exp }}$ & $\begin{array}{l}\alpha=\alpha_{1}, n=n_{1} \\
\operatorname{ERI}(\%)\end{array}$ & $\begin{array}{l}\alpha=\alpha_{0} n=n_{0} \\
\operatorname{ERI}(\%)\end{array}$ \\
\hline 118 & 39 & 118 & 39 & 2356000 & -60 & -1 \\
\hline 121 & 40 & 121 & 40 & 1516000 & -49 & 26 \\
\hline 130 & 43 & 130 & 43 & 378000 & 16 & 188 \\
\hline 121 & 121 & 121 & 121 & 803000 & -52 & -37 \\
\hline 124 & 124 & 124 & 124 & 366000 & -12 & 15 \\
\hline 130 & 130 & 130 & 130 & 210000 & 5 & 38 \\
\hline 140 & 140 & 140 & 140 & 117000 & 5 & 38 \\
\hline
\end{tabular}

Table 12 Error Indexes of different mean stress models under multiaxial fatigue loading ( $(\mathrm{3} 355 \mathrm{~J} 0$ alloy steel)

\begin{tabular}{llllllll}
\hline \multicolumn{1}{l}{ Marin's mean stress model } & & & & \\
\\
\end{tabular}

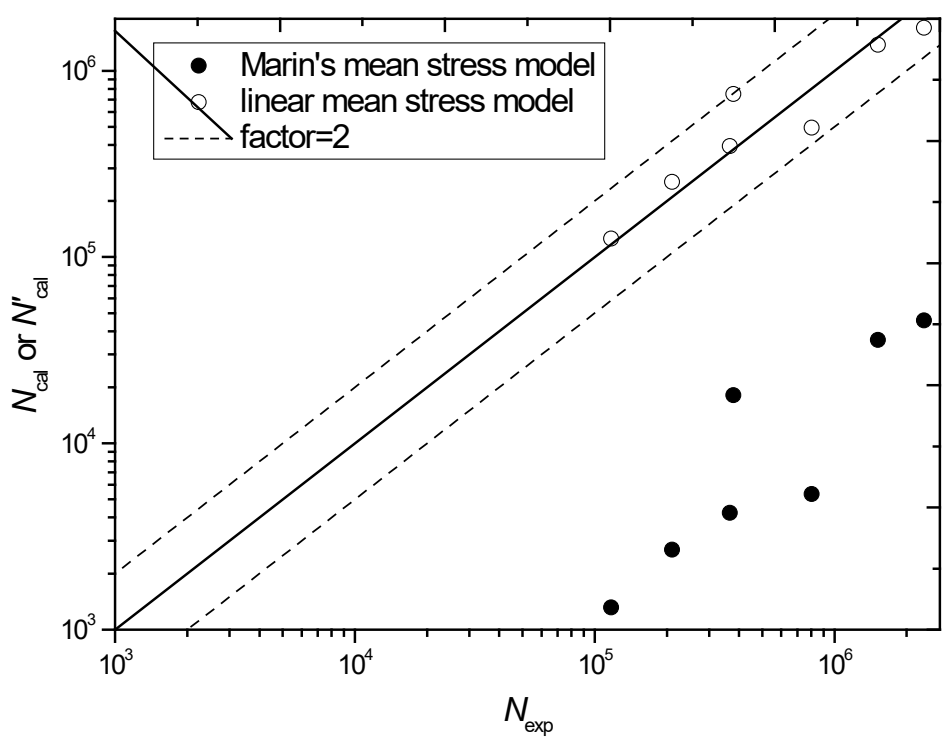

Figure I Comparison of fatigue lives predicted by the linear mean stress model and the Marin's mean stress model under multiaxial fatigue loading with nonzero mean stress.

Citation: Yan X.A mean stress model of fatigue life of metal materials under multiaxial loading. Material Sci \& Eng. 2021;5(2):60-69.

DOI: 10.15406/mseij.2021.05.00157 


\section{Concluding remarks}

On basis of the present investigation, it can be seen that:

a) 1、For some metal materials, for example, Cast Iron, an accuracy of fatigue lives predicted by means of the linear mean stress model and the Marin's mean stress model is very high and the two models almost have same accuracy.

b) 2、For S355J0 alloy steel, under the axial and pure shear fatigue loading, an accuracy of fatigue lives predicted by means of the linear mean stress model and the Marin's mean stress model is very high. But under the multiaxial fatigue loading, an accuracy of fatigue lives predicted by using the Marin's mean stress model is very poor, while on the contrary, fatigue lives predicted by means of the linear mean stress model are very satisfactory. On basis of the two points above, the author considers that the linear mean stress model presented in this paper is more suitable than the Marin's mean stress model in performing the fatigue life assessment. Up to date, as well known to us, the Marin's mean stress model has been widely used to perform the fatigue life assessment of metal materials with mean stress effect.

Why is the linear mean stress model, which, in the mathematical formula, has no an advantage over the Marin's mean stress model, presented in this paper? The reason is on basis of the following two aspects:

A. By using the Marin's mean stress model, the author ever attempted to propose a multiaxial fatigue limit model, and found that numerical computation difficulty occurred sometimes in determining material constants in the Marin's mean stress model.

When non-proportional loading fatigue is carried out, Itoh's formula ${ }^{19}$ is usually used to reveal the relationship of the amplitude of the equivalent non-proportional stress, $\sigma_{\text {ean }}$, and the amplitude of the effective proportional stress, $\sigma_{e a}$, i.e.,

$$
\sigma_{e a n}=\sigma_{e a}(1+\beta F)
$$

where $\beta$ is material sensitivity parameter to load-path nonproportionality defined on $\sigma-\sqrt{3} \tau$ stress plane; $F$ is usually called a non-proportional loading factor which expresses the severity of non proportional loading. The author finds that the prediction results of fatigue life obtained by using Itoh's formula sometimes are not satisfactory. Thus the following attempt is made:

$$
\sigma_{e a n} / \sigma_{e a}=\lambda+\gamma F
$$

where $\lambda, \gamma$ are constants to be determined by linear fitting of $\sigma$ and $F$. Obviously, the Itoh's formula (24) has mechanical advantage over the linear formula (25). But verification by experimental data of fatigue life of metallic materials shows that the accuracy of fatigue lives predicted by means of the linear formula (25) is higher than that by the Itoh's formula (24), which will be reported in another paper.

\section{Acknowledgments}

None.

\section{Conflicts of interest}

The authors declare that there is no conflict of interest.

\section{References}

1. Liu BW, Yan XQ. A new model of multiaxial fatigue life prediction with influence of different mean stresses. International Journal of Damage Mechanics. 2019;28(9):1323-1343.

2. Liu BW, Yan XQ. A multiaxial fatigue limit prediction equation for metallic materials. ASME Journal of Pressure Vessel Technology. 2020.

3. Gough, HJ. Engineering steels under combined cyclic and static stresses. Proceedings of the Institution of Mechanical Engineers. 1949;160:417440.

4. Frith, PH. Fatigue of wrought high-tensile alloy steel. Proceedings of the Institution of Mechanical Engineers. 1956;462-499.

5. Cristofori A, Susmel L, Tovo R. A stress invariant based criterion to estimate fatigue damage under multiaxial loading. International Journal of Fatigue. 2008;30:1646-1658.

6. Papadopoulos IV, Davoli P, Gorla C, et al. A comparative study of multiaxial highcycle fatigue criteria for metals. Int J Fatigue. 1997;19:219-235.

7. Sines G. Behaviour of metals under complex static and alternating stresses. In: Metal Fatigue, McGraw Hill, New York. 1959:145-169.

8. Crossland B. Effect of large hydroscopic pressures on the torsional fatigue strength of an alloy steel. Proceedings of international conference on fatigue of metals; London, New York. 1956. p. 138-49.

9. Li B, De Freitas M. A procedure for fast evaluation of high cycle fatigue under multiaxial random loading. J Mech Design. 2002;124:558-563.

10. Wang $\mathrm{CH}$, Brown MW. Multiaxial random load fatigue: life prediction techniques and experiments. Fourth international conference on biaxial/ multiaxial fatigue, May 31-June 3, Paris. 1994.

11. Susmel L, Lazzarin P. A bi-parametric modified Wöhler curve for high cycle multiaxial fatigue assessment. Fatigue and Fracture of Engineering Materials and Structures. 2002;25:63-78.

12. Papadopoulos IV, Davoli P, Gorla C, et al. A comparative study of multiaxial high-cycle fatigue criteria for metals. Int J Fatigue. 1997;19:219-235.

13. Papadopoulos IV. Long life fatigue under multiaxial loading. Int $J$ Fatigue. 2001;23:839-849.

14. Tao G, Xia Z. Mean stress/strain effect on fatigue behavior of an epoxy resin. International Journal of Fatigue. 2007;29(12):2180-2190.

15. Marin J. Interpretation of fatigue strength for combined stresses. In: Proceedings of international conference on fatigue of metals. Institution of mechanical engineers; London. 1956. p. 184-194.

16. Berto F, Lazzarin P, Tovo R, Multiaxial fatigue strength of severely notched cast iron specimens. International Journal of Fatigue. 2014;67:15-27.

17. Gasiak G, Pawliczek R. The mean loading effect under cyclic bending and torsion of 18G2A steel. In: M de Freitas, editor. Proceedings of 6th International Conference on Biaxial/ Multiaxial Fatigue and Fracture; Lisbon, Portugal. 2001. p. 213-222.

18. Gasiak G, Pawliczek R. Application of an energy model for fatigue life prediction of construction steels under bending, torsion and synchronous bending and torsion. Int J Fatigue. 2003;25(12):1339-1346.

19. Itoh T, Sakane M, Ohnami M, et al. Nonproportional low cycle fatigue criterion for type 304 stainless steel. Transact ASME J Engng Mater Technol. 1995;117(3):285-292. 